\title{
LINHAGEM HUMANA DE SCHISTOSOMA MANSONI RESISTENTE A ESQUISTOSSOMICIDAS
}

\author{
L. C. de S. Dias* \\ R. J. Pedro* \\ E. Rigo: \\ M. M. F. (joto* \\ (j. L. Mafra ${ }^{\text {in }}$
}

Isoloti-se linhagen de $S$. mansoni proveniente de paciente (MAP) tratado conl hycanthone na dose de $2,5 \mathrm{mg} / \mathrm{Kg}$ 1. $\mathrm{M}$. em 2-1-75 e com oxamniquine na dose de 14,0 mg/Kg V. O. em 24-11-76. Miracídius das fezes deste paciente infectaram Biomphalaria glabrata, albinas, que eliminaram cercárias. Com estas infectaram-se 3 grupos de camundongos albinos ( 100 por animal, por via subcutânea) que após 50 dias foram tratados da seguinte maneira: grupu A com hycanthone $(80 \mathrm{mg} / \mathrm{Kg}$, I. M.), grupo $B$ com oxamniquine $(100 \mathrm{mg} / \mathrm{Kg}, \mathrm{V}$. O.) e grupo $C$ não tratados. Da mesma forma infectaram-se camundongos com cercárias da linhagem B $\mathrm{H}$ (mantida en laboratório) que foram tratados segundo closagens acima, constituindo os grupos D com hycanthone, $E$ com oxamniquine e $F$ não tratados. Após 10 dias do tratamento, per- fundirani-se os animais e toram feitos oogramas do intestino delgado. Na linhagem $\mathrm{B} \mathrm{H}$, nos grupos $\mathrm{D}$ e E, $98,0 \%$ dos vermes se localizaram nas veias intra-hepáticas e houve $100 \%$ de alteração dos oogramas (quando un ou mais estadios correspondentes a ovos imaturos estavam ausentes); no grupo F, 20,5\% dos vermes encontravam-se no figado e $0,0 \%$ de alteraçào dos oogramas. Na linhagen MAP, nos grupos $A, B$ e $C$, cerca de $85,0 \%$ dos vermes localizavam-se nas veias mesentéricas e $0,0 \%$ de alteração dos oogramas. Assin, demonstra-se resistência em linhagem de $S$. mansoni proveniente de paciente tratado por hycanthone e oxamniquine. Além da importância clinica do achado ressalta-se as implicaçóes epidemiológicas considerando-se que a resistência poderia ser transmitida a outras geraçōes do verme.

\footnotetext{
* Do Instituto de Biologia da Universidade de Campinas - UNICAMP - Caixa Postal 1.170 - 13100 - Campinas - SP - Brasil.
} 